\title{
黄河中下游影响区生态空间和生态指数变化评估
}

\author{
刘小燕 ${ }^{1,2,3}$, 崔耀平 ${ }^{1,2,3, *}$, 董金玮 ${ }^{4}$, 史志方 $^{1,3}$, 闰亚迪 ${ }^{1,3}$ \\ 1 黄河中下游数字地理技术教育部重点实验室 (河南大学), 开封 475004 \\ 2 河南省大气污染综合防治与生态安全重点实验室, 开封 475004 \\ 3 河南大学地理与环境学院, 开封 475004 \\ 4 中国科学院地理科学与资源研究所, 北京 100101
}

摘要:黄河中下游影响区人地关系复杂,受到自然和人类活动交叠影响, 厘清该区域的生态空间及其生态指数变化对实现黄河 流域生态保护与高质量发展这一国家战略具有重要意义。对黄河中下游影响区的生态空间时空格局演化和生态状况进行定量 分析,具体包括基于土地利用遥感监测数据的生态空间演变分析和基于纯遥感驱动的遥感生态指数 RSEI (Remote Sensing Ecological Index) 分析,从而完整刻画了 2000-2020 年黄河中下游影响区生态环境的动态变化格局。研究结果显示: (1) 从土地 利用类型变化来看,黄河中下游影响区主要土地利用类型是耕地,占研究区的 $70 \%$; 近 20 年以来耕地和建设用地变化明显,耕 地面积减少了 $2.15 \%$ (约 $9849 \mathrm{~km}^{2}$ ), 建设用地增加了 $30.75 \%$ (约 $11146 \mathrm{~km}^{2}$ ), 且建设用地的扩张主要以侵占耕地为主; (2) 从生 态空间类型变化来看, 研究区半生态用地面积变化较大, 主要向弱生态用地转变, 发生在城市地区; 天津市、河北省以及山东省 的沿海地区生态空间类型由弱生态用地转为生态用地; 黄河流域河南段可以明显看出半生态用地向生态用地的转变; (3) 从生 态级别来看,近 20 年来生态级别为“差” 和“较差” 的面积有所减少, 由 2000 年的 $38.85 \%$ 减少至 2020 年的 $23.01 \%$,生态级别为 “中等” 和“良”的面积有所上升,由 2000 年的 $45.54 \%$ 增加至 2020 年的 $73.71 \%$,生态级别为“优” 主要分布在河南省、江苏省和 安徽省周边; 黄河滩区内外生态环境质量相当,均呈缓慢上升趋势。本研究利用遥感大数据完整地对黄河中下游影响区的生态 空间及其对应生态状况进行了长时间序列的监测与评估,为总体认知和把握该区的生态状况提供了基础支撑。

关键词: 土地利用;生态空间;遥感生态指数; GEE; 时空分析

\section{Assessment of ecological space and ecological index changes in the affected area of the middle and lower reaches of the Yellow River}

\author{
LIU Xiaoyan ${ }^{1,2,3}$, CUI Yaoping ${ }^{1,2,3, *}$, DONG Jinwei ${ }^{4}$, SHI Zhifang ${ }^{1,3}$, RUN Yadi ${ }^{1,3}$ \\ 1 Key Laboratory of Geospatial Technology for the Middle and Lower Yellow River Regions (Henan University), Ministry of Education, Kaifeng \\ 475004, China \\ 2 Key Laboratory of Integrative Prevention of Air Pollution and Ecological Security of He'nan Province, Kaifeng 475004, China \\ 3 School of Geography and Environmental Science, He'nan University, Kaifeng 475004, China \\ 4 Institute of Geographic Sciences and Natural Resources Research, Chinese Academy of Sciences, Beijing 100101, China
}

\begin{abstract}
The human-land relationship in the affected area of the middle and lower reaches of the Yellow River is complex, and it is affected by overlapping natural and human activities. Clarifying the ecological space of the region and its ecological changes is of great significance to achieve the national strategy of ecological protection and high-quality development for the Yellow River Basin. In this study, we made a quantitative analysis on the evolution of ecological pattern and ecological

基金项目: 中国科学院战略性先导科技专项 (XDA19040301) ; 国家自然科学基金面上项目 (42071415); 中科院陆地表层格局与模拟院重点实验 室开放基金( LB2021006)

收稿日期:2020-07-06; 采用日期: 2021-08-10

*通讯作者 Corresponding author.E-mail: cuiyp@ lreis.ac.cn
\end{abstract}


status in the affected area of the middle and lower reaches of the Yellow River. Specifically, by analyzing the spatiotemporal evolution of ecological space with the data of land use and Remote sensing ecological index (RSEI) derived by remote sensing products, this study completely depicted the dynamic change pattern of ecological environment in the affected area of the middle and lower reaches of the Yellow River from 2000 to 2020. The results showed that: (1) from the perspective of the land use change, the main land use type in the study area was cultivated land, accounting for $70 \%$ of the study area. Over the past 20 years, cultivated land and construction land changed significantly. The area of cultivated land decreased by $2.15 \%\left(9849 \mathrm{~km}^{2}\right)$, and the construction land increased by $30.75 \%\left(11146 \mathrm{~km}^{2}\right)$, and the expansion of construction land was mainly by occupying cultivated land. (2) In terms of the ecological space, the areas of semiecological land changed greatly, mainly to weak-ecological land, which occurs in urban areas. The ecological space type in the coastal areas of Tianjin, Hebei, and Shandong changed from weak-ecological land to ecological land. The transition from semi-ecological land to ecological land appeared obviously in the Henan section of the Yellow River Basin. (3) For the RSEI, the area proportion with low level RSEI decreased from $38.85 \%$ in 2000 to $23.01 \%$ in 2020 while the area proportion with high level RSEI increased from $45.54 \%$ to $73.71 \%$ in recent 20 years. Relatively good ecological environment was mainly distributed around Henan, Jiangsu, and Anhui. The eco-environmental quality inside and outside the Yellow River beach area was similar, showing a slow upward trend. In this study, ecological space and its corresponding ecological status in the affected areas of the middle and lower reaches of the Yellow River were monitored and evaluated over a long time series based on the remote sensing big data, which provided the foundation support for the overall cognition and characterization for the ecological dynamics of the study area.

Key Words: land use; ecological space; remote sensing ecological index; Google Earth Engine; spatio-temporal analysis

黄河流域生态保护和高质量发展已经上升为国家重大战略,黄河生态保护与治理势在必行 ${ }^{[1]}$ 。良好的 流域生态环境是实现可持续发展的前提条件,但是黄河流域,特别是黄河中下游影响区人地关系非常复杂, 尤 其是近年来随着社会的不断发展, 城市化进程不断加快等人类活动叠加自然干扰造成的生态环境问题日益突 出 ${ }^{[2]}$ 。因此, 监测黄河中下游影响区生态状况、评估生态环境变化特征也成为当前迫切需要面对的问题 ${ }^{[3]}$ 。

生态环境监测和评估方法较多, 但缺乏利用遥感作为全数据链评估黄河中下游影响区生态状况的相关研 究 ${ }^{[4]}$ 。遥感技术具有快速、时实、大面积等优点已经被广泛地应用于生态环境领域 ${ }^{[5]}$, 成为监测和评估区域 生态环境的有效手段 ${ }^{[6]}$ 。特别是遥感大数据平台的出现, 能够对海量数据进行快速处理和分析, 对生态环境 的实时监测和评估提供帮助。

21 世纪以来国内外研究学者利用遥感技术, 通过构建指数模型对区域生态环境的监测和评估开展了大 量研究, 指数模型主要包括: EI 指数 ${ }^{[7]}$ 、DPSIR-TOPSIS 模型 ${ }^{[8]}$ 和 AHP-Grey 的动态生态环境评价模型 ${ }^{[9]}$ 等, 丰 富了生态环境监测和评估的方法。但是以往这些研究存在影响因子选择单一或模型构建受到人为因素的影 响等问题, 对生态环境的监测和评估的精度有一定影响。而徐涵秋 ${ }^{[10]}$ 提出的一种包含湿度、绿度、干度和热 度等因素综合反映的遥感生态指数 (Remote Sensing Ecological Index, RSEI), 避免人为因素对研究结果产生的 影响, 提高了研究结果的客观性。近几年该指数在漓江流域 ${ }^{[11]}$ 、长三角城市群 ${ }^{[12]}$ 以及整个中国区 ${ }^{[13]}$ 都有相 应研究, 因此, RSEI 指数是一种普遍接受的可以在大范围内进行对比的方法, 适宜进行大尺度, 也适宜进行与 他人做横向比较。但目前对黄河中下游影响区生态环境的研究更多关注某一影响因子对生态环境的影响 ${ }^{[14]}$ 及早期黄河流域生态环境状况 ${ }^{[15-16]}$, 缺少对近些年黄河故道等地区生态空间变化及生态状况的整体监测和 评估,此外,对黄河有记载以来所流经地区的近 20 年生态状况及其差异性仍不得而知。

本研究基于遥感大数据平台、遥感数据以及土地利用分类数据,利用生态空间分类体系和 RSEI 模型, 分 析 2000 年以来黄河中下游影响区生态空间类型及生态指数的时空变化规律, 并对该地区的生态环境进行监 测和评估。 


\section{1 数据来源与研究方法}

\section{1 研究区界定}

本研究涉及到的黄河中下游影响区是指包括黄河中下游流域在内的五省一市,即河南、河北、山东、安徽、 江苏以及天津的部分地区 ${ }^{[17]}$ 。研究区选择主要是依据有记载以来, 黄河所流经区域 (图 1)。2600多年 来 ${ }^{[18]}$, 黄河下游河道经历了从北到南, 又从南到北的大循环摆动。下游故道略呈折扇形, 最北经由今河北霸 州市、天津海河人海, 最南经由安徽、江苏夺淮河人海 (在江苏省经过中山河与黄河故道在滨海县人海)。因 此, 研究区不仅仅局限于黄河当前的流域范围, 更多关注为黄河流域的影响范围, 既包括当前的黄河河道及黄 河流域范围, 还考虑历史的黄河故道及其流域波及范围。研究区地理位置在 $32^{\circ} 25^{\prime}-39^{\circ} 21^{\prime} \mathrm{N}$ 和 $119^{\circ} 25^{\prime}-$ $110^{\circ} 10^{\prime} \mathrm{E}$, 研究区总面积 26.72 万 $\mathrm{km}^{2}$, 该区域位于华北平原, 地势平坦, 属于暖温带半干旱季风气候, 夏季温 暖多雨, 冬季寒冷干燥。

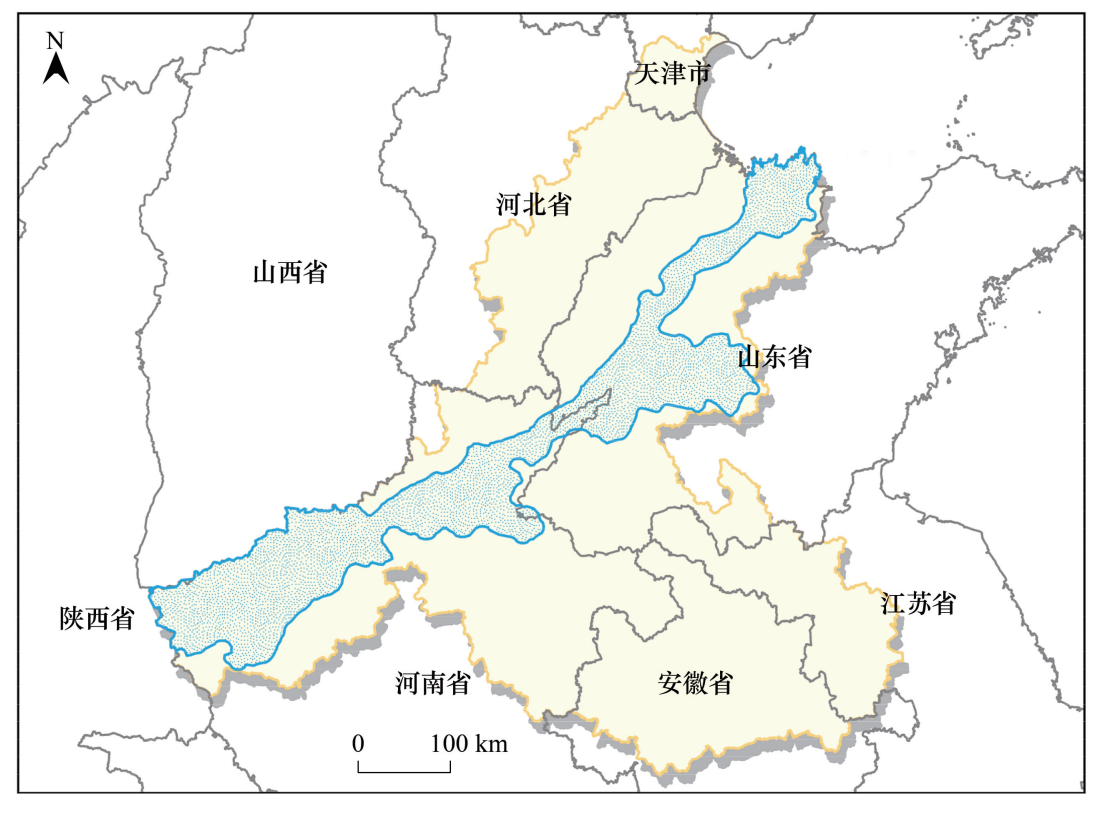

黄河流域 $\square$ 黄河中下游影响区

省级行政区

图 1 黄河中下游影响区

Fig.1 Affected area in the middle and lower reaches of the Yellow River

\section{2 研究数据}

土地利用遥感观测数据。本研究土地利用类型数据来自于中国科学院资源与环境数据中心 ${ }^{[19]}$, 涉及 2000 年和 2020 年的两期影像, 空间分辨率为 $1 \mathrm{~km}$ 。原始数据来主要来自 Landsat 影像, 选取影像时尽量避免 云雾干扰, 以无云或者少云的准备生长季影像为主 ${ }^{[20]}$ 。对遥感影像进行几何校正和图像增强处理,建立图像 解译标志 ${ }^{[21]}$ 。土地利用类型分为耕地、林地、草地、水域、建设用地、未利用地等 6 个一级类。两期遥感影像 分类准确度为 $92.4 \%$ 和 $93.2 \%$, 满足本研究要求 ${ }^{[22]}$ 。

MODIS 影像数据。采用空间分辨率为 $500 \mathrm{~m}$ 、时间分辨率为 $8 \mathrm{~d}$ 的 MOD09A1 地面反射率数据, 对该数据 进行辐射定标和几何校正等基本处理, 其消除大气散射、吸收、反射引起的部分误差, 为地表实际反射 率 ${ }^{[23-24]}$ 。本研究同时利用 MOD11A2 V6 数据提供的空间分辨率为 $1 \mathrm{~km}$ 的 $8 \mathrm{~d}$ 平均地表温度数据。

\section{3 研究方法}

\subsection{1 生态空间定义及变化分析}

《生态保护红线划定指南》中对生态空间定义为指具有自然属性、以提供生态服务或生态产品为主体功 
能的国土空间,包括森林、草原、湿地等。这一定义更多的是从国土空间规划或生态红线的角度,早前学术界 就生态空间展开过深入研究,但目前并未对生态空间的概念与分类达成共识。而本研究从生态评估角度参考 最新学者 ${ }^{[25]}$ 对生态空间的定义,该生态空间的界定不仅考虑了国土资源的生态空间定义,还包括了建设用地 和耕地等受到人为干扰强烈的土地范围,即本研究涉及的生态空间不仅是把生产和生活用地也看作承载着城 镇和农田生态系统的空间范围统一加以考虑。因此,本研究基于土地利用类型衍生出三种生态用地类型:生 态用地、半生态用地和弱生态用地 (表 1)。

表 1 生态空间分类及与土地利用类型的映射关系

Table 1 Ecological space classification system and its corresponding land use/land cover classification

\begin{tabular}{|c|c|c|c|}
\hline $\begin{array}{l}\text { 用地类型 } \\
\text { Class }\end{array}$ & $\begin{array}{l}\text { 含义 } \\
\text { Description }\end{array}$ & $\begin{array}{l}\text { 名称 } \\
\text { Name }\end{array}$ & $\begin{array}{l}\text { 分类依据 } \\
\text { Classification standard }\end{array}$ \\
\hline $\begin{array}{l}\text { 生态用地 } \\
\text { Ecological land }\end{array}$ & $\begin{array}{l}\text { 完全生态用地或生态功能 } \\
\text { 较其它功能强 }\end{array}$ & $\begin{array}{l}\text { 林地 } \\
\text { 草地 } \\
\text { 水域 } \\
\text { 未利用地 }\end{array}$ & $\begin{array}{l}\text { 林地具有水源涵养、气候调节、防风固沙等重要作用, 草地具有 } \\
\text { 土壤保持、气候调节、自然景观等生态服务功能, 水域具有调节 } \\
\text { 区域气候和水文等作用, 未利用地多为天然的生态类型, 其它 } \\
\text { 用地在固定流沙、减弱风蚀、改善生态环境质量等方面作用明 } \\
\text { 显。以上用地类型具原生植被或景观特征, 生态价值十分重要 }\end{array}$ \\
\hline $\begin{array}{l}\text { 半生态用地 } \\
\text { Semi-ecological land }\end{array}$ & 生态功能较其它功能相当 & 耕地 & $\begin{array}{l}\text { 耕地首先具有较强的食物供给功能, 同时也具有较强的气候调 } \\
\text { 节、碳固定等生态功能 }\end{array}$ \\
\hline $\begin{array}{l}\text { 弱生态用地 } \\
\text { Weak-ecological land }\end{array}$ & 生态功能极弱 & 建设用地 & $\begin{array}{l}\text { 城镇用地、农村居民点及其它建设用地主要以生产和生活功能 } \\
\text { 为主 }\end{array}$ \\
\hline
\end{tabular}

本研究基于土地利用类型衍生的生态空间分类体系,通过叠加运算实现图谱融合对研究区生态空间类型 变化进行统计分析 ${ }^{[26]}$ 。具体步骤为: 1 ) 对经过分类后的土地利用数据集进行重分类,设置生态用地、半生态 用地和弱生态用地三类编码分别为 $1 、 2 、 3 ; 2)$ 将前一时刻的栅格单元的编码作为十位数, 后一时刻的栅格单 元的编码作为个位数,生成一个两位数编码的生态空间图谱单元。最终得到 2000-2020 年黄河中下游影响 区生态空间变化图谱。

\subsubsection{RSEI 指标计算及变化分析}

RSEI 是一种完全基于遥感数据得到的综合分析区域生态环境的方法, 可以客观反映区域的生态环境质

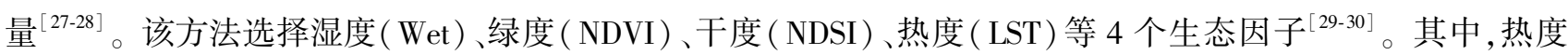
指标 LST 数据利用同源的 MODIS 地表温度产品插补得到完整的 LST 数据 ${ }^{[31]}$, 其余指标公式如下:

$$
\text { RSEI }=\mathrm{f}(\text { Wet }, \text { NDVI }, \text { LST }, \text { NDBSI })
$$

$$
\begin{aligned}
& \text { Wet }=0.10839 \rho_{1}+0.0912 \rho_{2}+0.5065 \rho_{3}+0.4040 \rho_{4}-0.2410 \rho_{5}-0.4658 \rho_{6}-0.5306 \rho_{7} \\
& \text { NDVI }=\left(\rho_{2}-\rho_{1}\right) /\left(\rho_{2}+\rho_{1}\right) \\
& \text { NDSI }=(\text { IBI }+S I) / 2 \\
& \text { IBI }=\frac{2 \rho_{6} /\left(\rho_{6}+\rho_{2}\right)-\left[\left(\rho_{2} /\left(\rho_{2}+\rho_{1}\right)+\rho_{4} /\left(\rho_{4}+\rho_{6}\right)\right.\right.}{2 \rho_{6} /\left(\rho_{6}+\rho_{2}\right)+\left[\left(\rho_{2} /\left(\rho_{2}+\rho_{1}\right)+\rho_{4} /\left(\rho_{4}+\rho_{6}\right)\right.\right.} \\
& S I=\frac{\left(\rho_{6}+\rho_{1}\right)-\left(\rho_{2}+\rho_{3}\right)}{\left(\rho_{6}+\rho_{1}\right)+\left(\rho_{2}+\rho_{3}\right)}
\end{aligned}
$$

式中, $\rho_{1-7}$ 代表 MODIS 第 1-7 波段的地表反射率。SI 表示土壤指数, IBI 表示建筑指数。由于四个指标量纲 不统一, 为了减小对研究结果的影响, 最终是将各指标的值进行归一化处理, 使其变换到 $0-1$ 之间 ${ }^{[32]}$, 公式 如下:

$$
N_{I}=\frac{I-I_{\min }}{I_{\max }-I_{\min }}
$$

式中, $N_{I}$ 为归一化指标, $I$ 为原始指标, $I_{\text {min }}$ 为指标 $I$ 最小值, $I_{\text {max }}$ 为指标 $I$ 最大值。

之后对四个指标通过主成分分析方法进行合成, 并选取得到的第一主成分作为 RSEI 指数 ${ }^{[13]}$ 。根据 
RSEI 模型计算出研究区 2000-2020 年 RSEI 值, RSEI 值越高, 表示生态空间状况越好。为了更直观地反映 研究区生态空间状况, 根据《生态环境评价技术规范》中生态环境分级标准 ${ }^{[3]}$, 进一步将 RSEI 值以 0.2 为间隔 划分为 5 个等级, 分别代表生态状况差 $(0-0.2)$ 、较差 $(0.2-0.4)$ 、中等 $(0.4-0.6)$ 、良 $(0.6-0.8)$ 、优 $(0.8-$ 1) 5 个等级。

\section{2 研究结果}

2.1 生态空间演变的时空特征

通过对研究区 2000 年和 2020 年土地利用分布变化进行统计,获得研究区不同时段各土地利用类型分布 及其变化情况 (图 2, 图 3)。结果表明研究区主要土地利用类型是耕地, 且分布较广泛, 2000 年和 2020 年耕 地面积分别占研究区总面积的 $71.37 \%$ 和 $67.91 \%$,近 20 年间面积共减少 $9849 \mathrm{~km}^{2}$, 减少速度为 $469 \mathrm{~km}^{2} / \mathrm{a}$; 研 究区林地分散度较小, 集中分布在河南省西南一带, 与 2000 年林地面积相比, 2020 年面积共减少 $805 \mathrm{~km}^{2}$; 研 究区草地主要分布在林地外围, 此外山东省北部和南部也分布大量草地, 草地面积同样有所减少, 共减少 $1878 \mathrm{~km}^{2}$, 减少速度为减少 $89 \mathrm{~km}^{2} / \mathrm{a}$; 水域主要包括黄河、天津市的北大港水库和团泊洼水库、山东省微山湖以 及江苏省的洪泽湖和高邮湖, 面积共增加 $1662 \mathrm{~km}^{2}$, 增速为 $79 \mathrm{~km}^{2} / \mathrm{a} ; 2000$ 年建设用地只集中在城区, 2020 年 可以明显看到建设用地以各自为中心向外扩大, 近 20 年建设用地面积共增加 $11146 \mathrm{~km}^{2}$, 增速为 $531 \mathrm{~km}^{2} / \mathrm{a}$, 其 中河南省郑州市、山东省济南市以及天津市建设用地面积明显增大; 未利用地主要包括自然保护区和湿地公 园等, 主要分布在河北省北部边界和山东省北部边界, 自 2000 年至 2020 年面积共减少 $1175 \mathrm{~km}^{2}$, 增速为 $56 \mathrm{~km}^{2} / \mathrm{a}$ 。
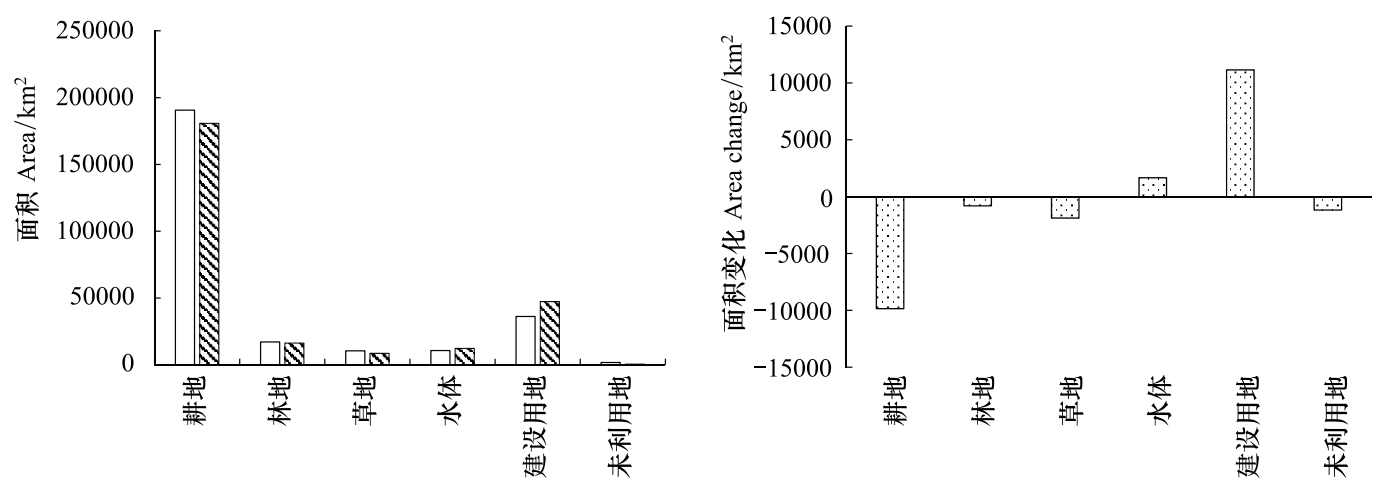

土地利用类型 Land use

图 22000 年和 2020 年土地利用类型变化统计

Fig.2 Statistics of land use type change in 2000 and 2020

2000-2020 年研究区生态空间用地发生了不同程度的变化 (图 4)。“半生态用地 $\rightarrow$ 弱生态用地” 占比最 大, 占总变化面积的 $41.78 \%$, 面积为 $32452 \mathrm{~km}^{2}$, 即平均每年有 $1545 \mathrm{~km}^{2}$ 地区由耕地转为建设用地; 其次为 “弱 生态用地 $\rightarrow$ 半生态用地” “生态用地 $\rightarrow$ 半生态用地” 和 “半生态用地 $\rightarrow$ 生态用地”, 面积分别为 $21927 \mathrm{~km}^{2}$ 、 $10154 \mathrm{~km}^{2}$ 和 $8927 \mathrm{~km}^{2}$, 占比分别为 $28.21 \% 、 13.06 \%$ 和 $11.48 \%$ 。山东省和河南省生态空间类型转换的面积较 多,转换面积分别为 $23455 \mathrm{~km}^{2}$ 和 $24513 \mathrm{~km}^{2}$, 且多以 “半生态用地 $\rightarrow$ 弱生态用地” 为主, 天津市生态空间类型转 换面积较少,共转换 $1920 \mathrm{~km}^{2}$; “弱生态用地 $\rightarrow$ 生态用地” 类型主要集中在天津市和山东省北部边界, “生态用 地 $\rightarrow$ 半生态用地” 主要集中在黄河人海口区域 (山东省东营市), 而河南省主要以“半生态用地 $\rightarrow$ 弱生态用地” 和“半生态用地 $\rightarrow$ 生态用地”为主, 其中 “半生态用地 $\rightarrow$ 弱生态用地” 主要集中在河南省的郑州市和洛阳市, 而 “半生态用地 $\rightarrow$ 生态用地” 主要分布在河南省黄河流域一带, 呈狭长分布。

\section{2 生态指数时空变化}

统计研究区 2000-2020 年 RSEI 分布变化情况并进行趋势线分析和显著性检验。从图 5 中可以看出,生 


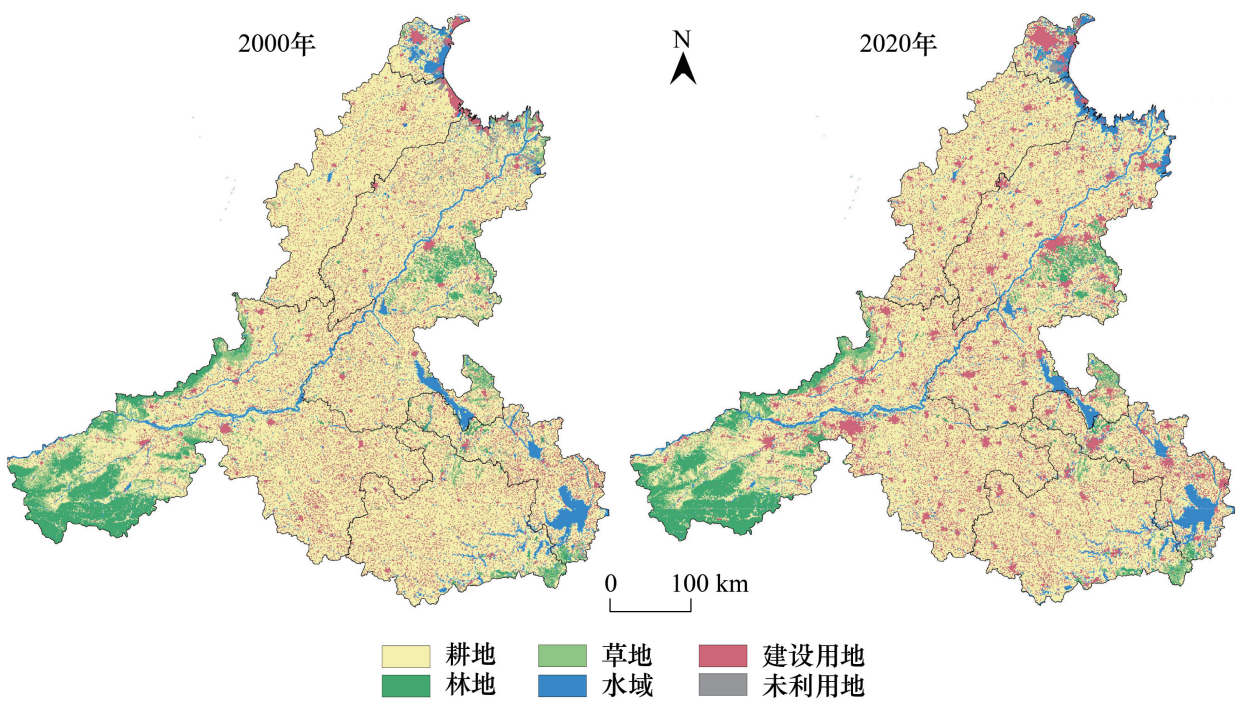

图 32000 年和 2020 年土地利用类型分布

Fig.3 Distribution of land use types in 2000 and 2020

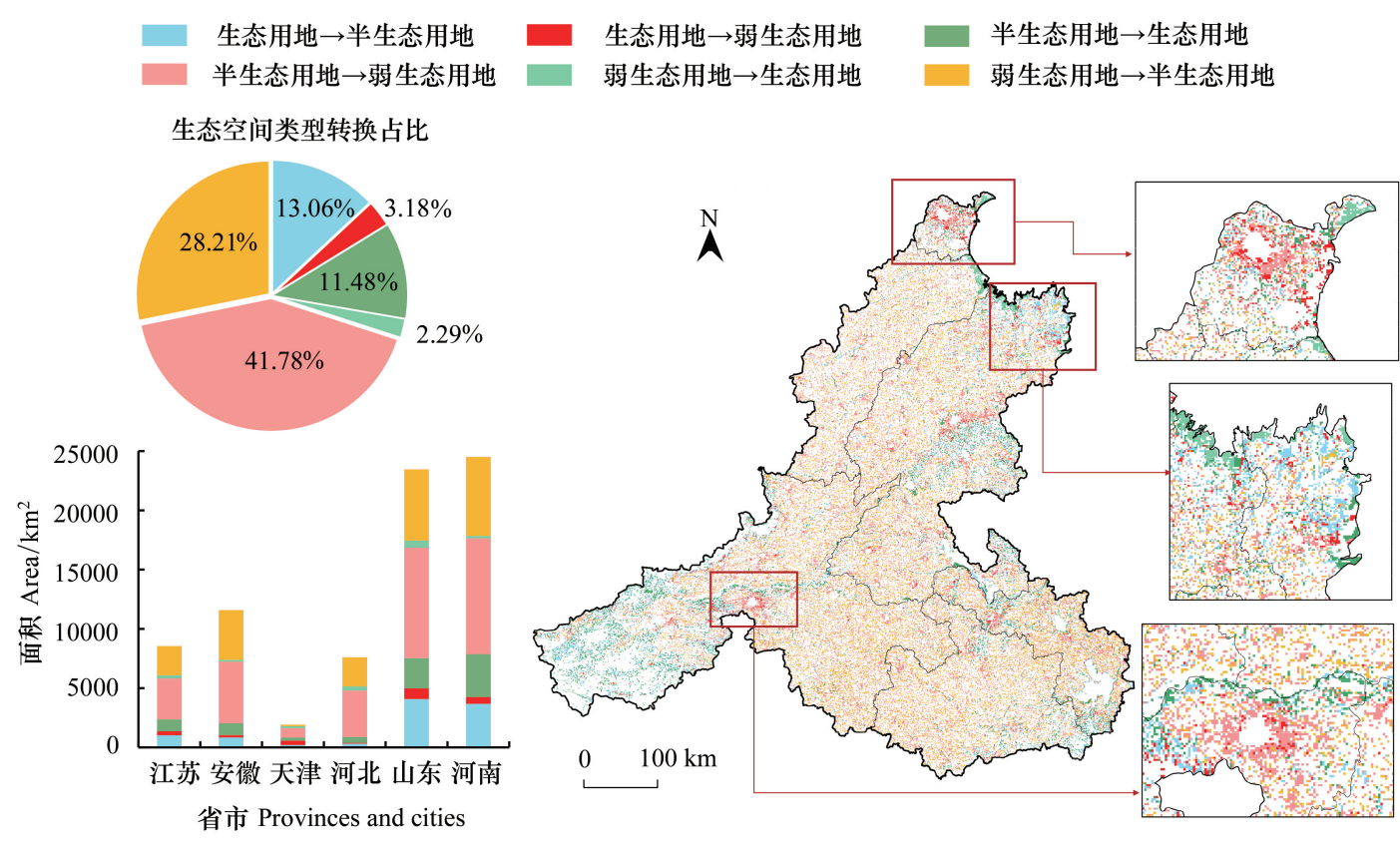

图 4 生态空间类型转换

Fig.4 Ecological space type transformation

态级别为“优”主要分布在河南省、江苏省和安徽省周边; 研究区中部生态级别主要为“中等” 和“良”; 研究区 北部生态级别以 “较差” 为主, 只有北部边界一带生态级别为 “差”。通过利用线性趋势分析法了解研究区时 空变化趋势, 分析结果表明生态指数变化较小的地区主要集中在研究区中部,而研究区北部和南部生态状况 变化较大,且通过了 0.01 显著性检验。

统计研究区各生态级别面积, 以便对研究区生态质量进行评估。结果表明: 研究区 2000-2020 年生态级 别为“中等”、“良”的研究区面积整体呈上升趋势, 2000-2020 年两者面积分别增加 $52956 \mathrm{~km}^{2}$ 和 $39296 \mathrm{~km}^{2}$, 从 2000 年占比 $36.60 \%$ 和 $8.94 \%$ 增加至 2020 年的 $52.77 \%$ 和 $20.94 \%$, 而生态级别为 “较差” 呈下降趋势, 面积 


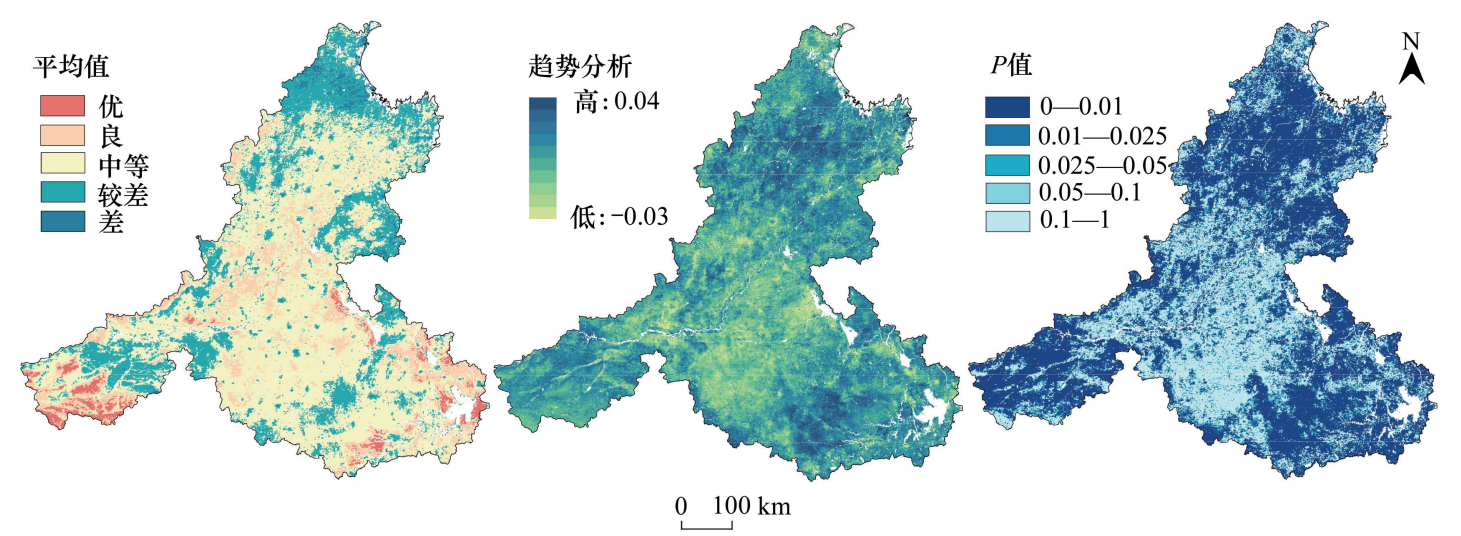

图 52000 -2020 年研究区 RSEI 变化分析

Fig.5 Change analysis of RSEI from 2000 to 2020

共减少 $41593 \mathrm{~km}^{2}$, 由 2000 年的 $32.92 \%$ 减少至 2020 年 的 $20.21 \%$; 生态级别为 “差” 的研究区面积整体呈下降 趋势, 由 2000 年的 $5.93 \%$ 减少至 2020 年的 $2.80 \%$; 生态 级别为 “优” 的研究区面积整体处于缓慢增长状态, 近 20 年共增加 $9979 \mathrm{~km}^{2}$, 由 2000 年的 $0.23 \%$ 增加至 2020 年的 $3.28 \%$ (图 6)。

2000-2020 年研究区内各省市生态空间类型发生 不同程度变化,但 RSEI 整体呈稳健增长趋势。2005 年 RSEI 均值达到最小 (0.39), 生态级别为 “较差”, 而 2018 年 RSEI 均值达到最大 $(0.52)$, 生态级别为 “中 等”, 说明研究区生态环境质量有所提高 (图 7)。统计 研究区五省一市每年 RSEI 变化,结果显示各省市 RSEI

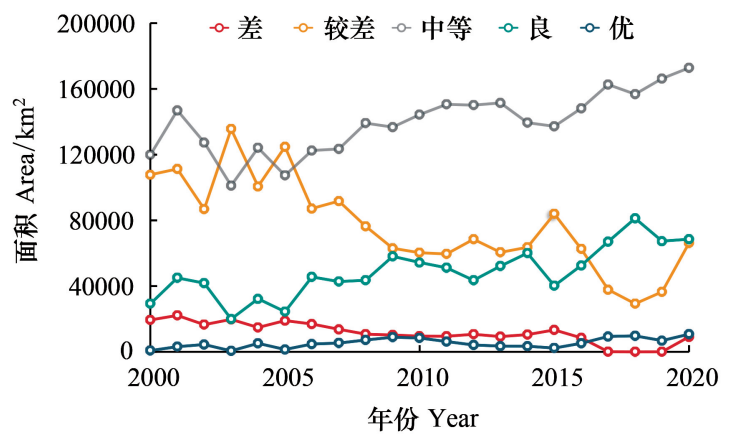

图 62000 - 2020 年不同生态等级面积动态变化

Fig. 6 The dynamics of various ecological grades from 2000 to 2020 均呈现缓慢增长趋势, 其中江苏省和河南省生态环境较 好,生态级别整体处于 “中等”, RSEI 分别为 $0.54 、 0.49$, 山东省、安徽省和河北省生态级别由 “较差” 转为 “中 等”,RSEI 分别增长 $0.14 、 0.05$ 和 $0.17,2000-2015$ 年天津市的 RSEI 在 0.3 之间平稳波动,但 2015 年之后,天 津市 RSEI 急剧上升, RSEI 由 2015 年的 0.26 上升为 0.56 。

统计研究区黄河流域内外 2000-2020 年 RSEI 变化情况 (图 8), 得到黄河流域内外 RSEI 均呈波动上升 趋势, RSEI 整体介于 $0.4-0.5$ 之间,生态级别整体为“中等”。图 8 可以看出流域内外 RSEI 平均值变化波动
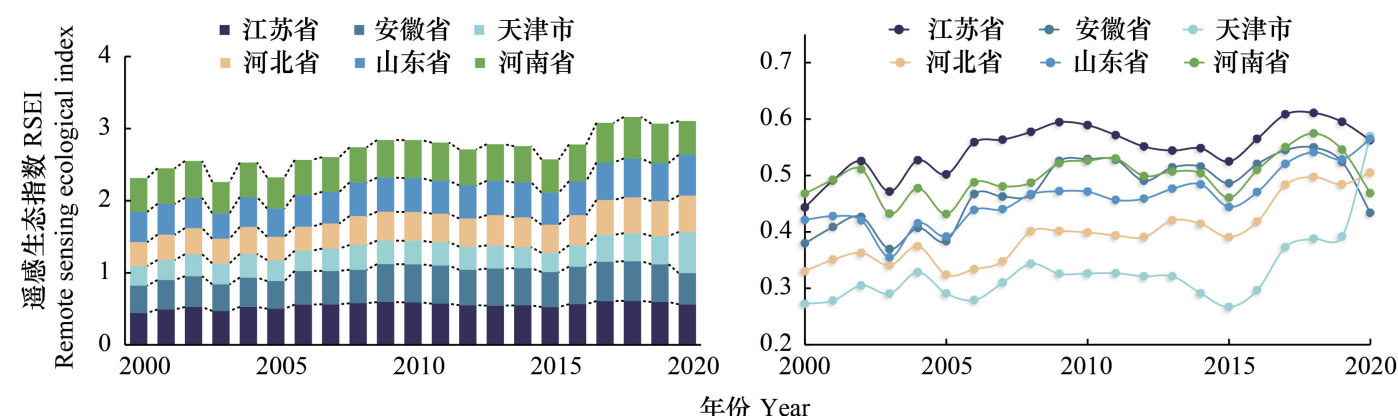

图 7 研究区各个省市生态空间类型 RSEI 变化图

Fig.7 RSEI changes in various provinces and ecological space types in the study area 
情况大体类似,2003 年流域内外 RSEI 最小, RSEI 分别 为 0.40 和 0.38 ,而 2018 年达到最大值 (0.56 和0.54); 多年来流域内外的 RSEI 变化趋势值均较小 $(0.007)$ 且 几乎无差异。就 2000-2020 年流域内外 RSEI 多年平 均而言, 黄河流域的 RSEI 为 0.479 , 大于流域之外的 0 . 469 。这说明了黄河流域内的生态状况虽然整体略好于 流域之外,但是流域内外的变化值均很小且变化趋势并 无明显差异。

2.3 不同生态空间类型内生态指数变化分析

2000-2020 年各生态空间类型的生态状况整体均 有所提升。图 9 表明 2000-2020 年期间 3 种生态空间

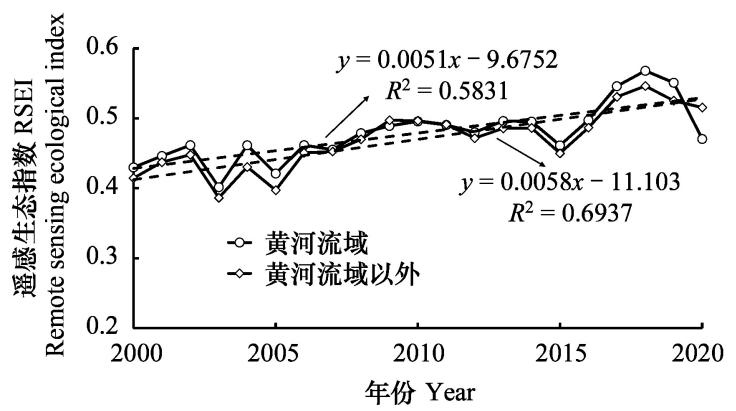

图 8 黄河流域内外年 RSEI 平均值年际变化

Fig.8 Annual change of RSEI in and outside the Yellow River basin 类型的 RSEI 均呈上升趋势, 表明生态用地区域的生态 保持整体向好、耕地生态功能增强及城市等人居生态环境均有所好转。3 种生态空间类型的 RSEI 主要集中 在 0.4-0.6 之间,生态级别整体为“中等”,2003 年 RSEI 达到近 20 年最小,而 2018 年 RSEI 达到最大。从图 9 中可以看出 2015 年之前各生态空间类型 RSEI 整体变化平稳, 整体波动幅度为 $0.04,2015$ 年之后 RSEI 急剧 上升,上升幅度为 0.2 。

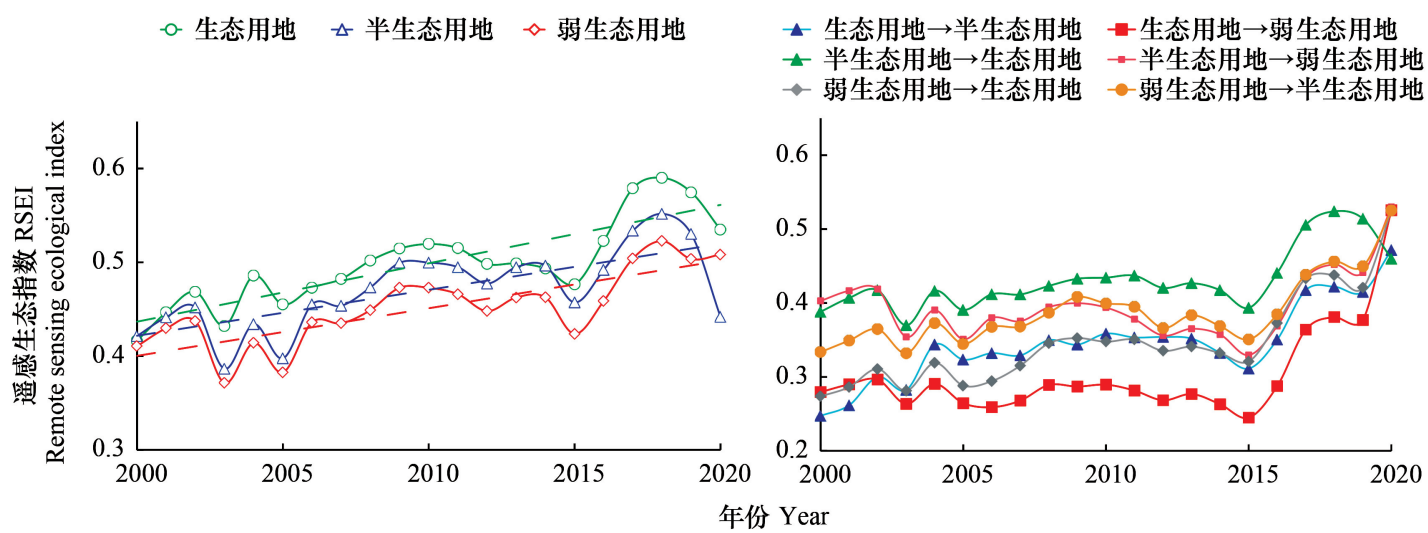

图 9 研究区各生态空间类型的 RSEI 变化

Fig.9 Annual RSEI change of various ecological space types

\section{3 结论与讨论}

\section{1 结论}

本研究利用土地利用数据衍生出的生态空间,并分析黄河中下游影响区生态空间类型变化;进一步,基于 Google Earth Engine 平台合成无云 MODIS 数据并通过主成分分析生成遥感生态指数 RSEI ${ }^{[33]}$, 进一步对研究 区生态指数的变化进行分析。本研究得到以下几点基本结论:

(1)生态空间用地类型变化中, “半生态用地 $\rightarrow$ 弱生态用地” 占比最大, 占总变化面积的 $41.78 \%$, 表明近 20 年城市的扩张主要以侵占农田为主,其次为 “弱生态用地 $\rightarrow$ 半生态用地”, 占比为 $28.21 \%$,表明在城市扩张 侵占农田的同时也会伴随着少部分其他生态类型转换为农田。

(2) 研究区 2000-2020 年生态状况整体有所改善,生态级别为“中等”、“良”和“优”的研究区面积整体 呈上升趋势, 而生态级别为“较差” 和“差”的面积呈下降趋势; 研究区各省份的生态状况也在持续改善,特别 是山东省、安徽省和河北省生态级别由“较差”转为“中等”。研究区黄河流域内外区域的 RSEI 均呈上升趋势 
且趋势基本一致,说明了黄河流域内外的生态状况几乎没有区别。

(3) 研究区生态用地、半生态用地和弱生态用地 RSEI 主要分布在 $0.4-0.6$ 之间,生态级别整体为 “中 等”。2000-2020 年 RSEI 整体均呈现线性上升趋势, 对应生态空间可知, 研究区林草地等生态用地的生态状 况持续向好、耕地的生态功能有所增强,城市等人居生态环境亦有所好转。

3.2 讨论

在整个研究过程中, 本研究完全利用了遥感手段和对应逐栅格的算法完成了数据处理与运算, 而没有任 何人为的权重设置、参数赋值等步骤。本研究搭建的研究框架能够快速地对 2000-2020 年来黄河中下游影 响区的生态状况进行定量评估, 且本研究所用 RSEI 与其他评估方法相比 ${ }^{[34-35]}$, 数据更容易获取和运算分析, 也使评估结果更为客观。

就结果而言,虽然研究区整体的生态状况持续改善,他人的研究也发现了在研究时段研究区植被具有增 强的趋势 ${ }^{[36-37]}$, 但要注意的是, 在逐栅格分析生态指数的变化趋势时, 发现在局部区域, 尤其是研究区中部还 存在很多地方生态指数下降。因此, 我们有必要审慎对待这段时期的生态好转状况, 尤其是植被绿度, 在全国 范围内均持续提升的大背景下 ${ }^{38]}$, 对生态空间的转换驱动因子及其对生态状态的影响因素与稳定性等方面 仍需进一步探索。

研究区生态状况复杂多样, 气候变化、人类行为 ${ }^{[39]}$ 以及政策变化 ${ }^{[40]}$ 都会对生态环境产生一定的影响, 本 研究 RSEI 指数虽考虑湿度、绿度、干度和热度等四种因素, 但并未考虑气候因子等对生态环境的影响。因此 在今后研究中, 应结合实际情况, 在现有研究的基础上添加气候因子等多种影响因素, 更加精确的对研究区的 生态环境状况进行监测和评估。

\section{参考文献 (References) :}

[ 1 ] 强海洋, 崔耀平. 黄河滩区综合治理与高质量管护研究. 中国国土资源经济, 2020, 33( 5) : 39-43.

[2] 刘立冰, 熊康宁, 任晓冬. 基于遥感生态指数的龙溪一虹口国家级自然保护区生态环境状况评估. 生态与农村环境学报, 2020, 36(2)： 202-210.

[ 3 ] 李红星, 黄解军, 梁友嘉, 王欢, 张一驰. 基于遥感生态指数的武汉市生态环境质量评估. 云南大学学报: 自然科学版, 2020, 42(1): 81-90.

[ 4 ] 宋慧敏, 薛亮. 基于遥感生态指数模型的渭南市生态环境质量动态监测与分析. 应用生态学报, 2016, 27(12): 3913-3919.

[ 5 ] 李述. 干旱、半干旱区土地利用/覆盖变化与荒漠化的遥感综合研究 $[D]$. 兰州: 兰州大学, 2006.

[ 6 ] 张红梅. 遥感与 GIS 技术在区域生态环境脆弱性监测与评价中的应用研究 [D ]. 福州: 福建师范大学, 2005.

[ 7 ] 姚尧, 王世新, 周艺, 刘瑞, 韩向娣. 生态环境状况指数模型在全国生态环境质量评价中的应用. 遥感信息, 2012, 27(3): 93-98.

[ 8 ] 徐美, 朱翔, 李静芝. 基于 DPSIR-TOPSIS 模型的湖南省土地生态安全评价. 冰川冻土, 2012, 34(5): 1265-1272.

[ 9 ] 夏军, 叶超, 魏洁, 姜鹏, 董军, 聂仕麟. 基于动态评估模型的绿色小水电生态环境影响研究. 水力发电, 2019, 45(10): 6-11, 19-19.

[10］徐涵秋. 区域生态环境变化的遥感评价指数. 中国环境科学, 2013, 33(5)：889-897.

[11] 魏雨涵, 钱建平, 范伟伟, 李彭. 基于 RSEI 的漓江流域生态环境质量动态监测. 中国水土保持科学, 2021, 19(1): 122-131.

[12] 郑子豪, 吴志峰, 陈颖彪, 杨智威, Marinello F. 基于 Google Earth Engine 的长三角城市群生态环境变化与城市化特征分析. 生态学报, 2021, 41(2): 717-729.

[13] 何盈利, 尤南山, 崔耀平, 肖桐, 郝媛媛, 董金玮. 2000 年来中国生态状况时空变化格局. 自然资源学报, 2021, 36(5): 1176-1185.

[14] 刘桂芳. 黄河中下游过渡区近 20 年来县域土地利用变化研究——以河南省孟州市为例 [D ]. 开封: 河南大学, 2009.

[15］卢勇, 余加红. 明末黄河中下游水利衰败与社会变迁(1573-1644). 云南社会科学, 2019, (2) : 162-173.

[16] 万欣. 基于 SPI 的黄河中下游地区干旱特征分析. 科学技术创新, 2019, (14) : 12-14.

[17] 王喜, 秦耀辰, 鲁丰先, 张黛, 姜向亚. 黄河中下游地区主要省份低碳经济发展水平的时空差异研究. 地理科学进展, 2013, 32(4)： 505-513.

[18］袁仲翔. 黄河之子回报黄河. 中州今古, 2001, (5) : 59-61.

[19] Liu J Y, Kuang W H, Zhang Z X, Xu X L, Qin Y W, Ning J, Zhou W C, Zhang S W, Li R D, Yan C Z, Wu S X, Shi X Z, Jiang N, Yu D S, Pan X Z, Chi W F. Spatiotemporal characteristics, patterns, and causes of land-use changes in China since the late 1980s. Journal of Geographical Sciences, 2014, 24(2): 195-210. 
[20］王金亮, 邵景安, 李阳兵. 近 20a 三峡库区农林地利用变化图谱特征分析. 自然资源学报, 2015, 30(2) : 235-247.

[21］张丽, 杨国范, 刘吉平. 1986-2012 年抚顺市土地利用动态变化及热点分析. 地理科学, 2014, 34(2) : 185- 191.

[22] 王思远, 刘纪远, 张增祥, 周全斌, 赵晓丽. 中国土地利用时空特征分析. 地理学报, 2001, 56(6): 631-639.

[23] 张元培, 吴颖, 罗军强, 胡青, 白洋, 郑雄伟, 宋长虹. 基于遥感生态指数的钟祥市生态变化分析. 资源环境与工程, 2019, 33(4)： 474- 480

[24] 李粉玲, 常庆瑞, 申健, 刘京. 黄土高原沟壑区生态环境状况遥感动态监测——以陕西省富县为例. 应用生态学报, 2015, 26(12)： 3811-3817.

[25]殷嘉迪，董金玮，匡文慧，崔耀平，江东. 20 世纪 90 年代以来中国生态空间演化的时空格局和梯度效应. 生态学报，2020，40(17)： 5904-5914.

[26] 宋开山, 刘殿伟, 王宗明, 张柏, 金翠, 李方, 刘焕军. 1954 年以来三江平原土地利用变化及驱动力. 地理学报, 2008, 63(1): 93-104.

[27] 徐涵秋. 水土流失区生态变化的遥感评估. 农业工程学报, 2013, 29(7): 91-97.

[28] 徐涵秋. 城市遥感生态指数的创建及其应用. 生态学报, 2013, 33(24) : 7853-7862.

[29] 林梦婧, 汪小钦, 肖爱芳, 王琳. 基于遥感生态指数的福建紫金山矿区生态评估. 福州大学学报: 自然科学版, 2020, 48(2)：230-235.

[30] Baig M H A B, Zhang L F, Shuai T, Tong Q X. Derivation of a tasselled cap transformation based on Landsat 8 at-satellite reflectance. Remote Sensing Letters, 2014, 5(5): 423-431.

[31] 李楠, 崔耀平, 刘素洁, 李家宝, 刘小萌, 石欣瑜, 邓晓晴. 基于多源遥感数据的地表温度空值插补. 测绘, 2018, 41(2): 57-61.

[32] XU H. A new index for delineating built-up land features in satellite imagery. International Journal of Remote Sensing, 2008, 29(14) : 4269-4276.

[33] 刘智才, 徐涵秋, 李乐, 唐菲, 林中立. 基于遥感生态指数的杭州市城市生态变化. 应用基础与工程科学学报, 2015, 23(4) : 728-739.

[34] 曾珍英, 江艳, 刘涛. 基于 Landsat_TM 影像的江西省生态环境质量状况研究. 安徽农业科学, 2010, 38(5): 2531- 2533.

[35] 朱嘉伟, 谢晓肜, 李心慧. 生态环境承载力评价研究——河南省为例. 生态学报, 2017, 37(21): 7039-7047.

[36] 田智慧, 张丹丹, 赫晓慧, 郭恒亮, 魏海涛. 2000-2015 年黄河流域植被净初级生产力时空变化特征及其驱动因子. 水土保持研究, $2019,26(2): 255-262$.

[37] Xiao J F, Zhou Y, Zhang L. Contributions of natural and human factors to increases in vegetation productivity in China. Ecosphere, 2015, 6(11) : 1-20.

[38] Chen C, Park T, Wang X H, Piao S L, Xu B D, Chaturvedi R K, Fuchs R, Brovkin V, Ciais P, Fensholt R, Tømmervik H, Bala G, Zhu Z C, Nemani R R, Myneni R B. China and India lead in greening of the world through land-use management. Nature Sustainability, 2019, 2(2): 122-129.

[39] 金凯, 王飞, 韩剑桥, 史尚渝, 丁文斌. 1982-2015 年中国气候变化和人类活动对植被 NDVI 变化的影响. 地理学报, 2020, 75(5)： 961-974.

[40］唐见, 曹慧群, 陈进. 生态保护工程和气候变化对长江源区植被变化的影响量化. 地理学报, 2019, 74(1): 76-86. 